\title{
Automated non-invasive identification of pelvic autonomic nerves with a handheld Raman spectrometer and potential application to nerve-sparing colorectal surgery: a preliminary study in surgical specimens
}

\author{
Sumito Sato ${ }^{1,2} \wedge$, Hirotada Kagoshima ${ }^{3}$, Manabu Shiozawa ${ }^{2}$, Suguru Nukada ${ }^{2}$, Kenta Iguchi ${ }^{2}$, Yo Mikayama ${ }^{2}$, \\ Takashi Oshima ${ }^{2}$, Masakatsu Numata ${ }^{4}$, Hiroshi Tamagawa ${ }^{4}$, Yasushi Rino ${ }^{4}$, Munetaka Masuda ${ }^{4}$, \\ Kuniya Tanaka ${ }^{1}$
}

${ }^{1}$ Department of Gastroenterological and General Surgery, Showa University Fujigaoka Hospital, Yokohama, Japan; ${ }^{2}$ Department of Gastrointestinal Surgery, Kanagawa Cancer Center, Yokohama, Japan; ${ }^{3}$ Rigaku Corporation, Tokyo, Japan; ${ }^{4}$ Department of Surgery, Yokohama City University, Yokohama, Japan

Contributions: (I) Conception and design: S Sato, H Kagoshima, K Tanaka; (II) Administrative support: Y Rino, M Shiozawa; (III) Provision of study materials or patients: S Sato, S Nukada, K Iguchi, Y Mikayama; (IV) Collection and assembly of data: S Sato, Y Rino, M Shiozawa, K Iguchi, Y Mikayama; (V) Data analysis and interpretation: S Sato, M Numata, H Tamagawa, T Oshima; (VI) Manuscript writing: All authors; (VII) Final approval of manuscript: All authors.

Correspondence to: Sumito Sato. Department of Gastroenterological and General Surgery, Showa University Fujigaoka Hospital, 1-30 Fujigaoka, Aoba-ku, Yokohama 241-8515, Japan. Email: su.sato@med.showa-u.ac.jp.

Background: Although minimally invasive surgery for colorectal cancer, whether performed as standard laparoscopic or robotic surgery, has been established as an oncologically safe procedure, postoperative urinary dysfunction and sexual dysfunction remain matters of concern, even when so-called nerve-sparing surgery is performed. We have hypothesized that Raman spectroscopy can be used intraoperatively as a noninvasive label-free means of objective identification of the pelvic nerves, and we conducted a preliminary study by applying a newly developed handheld Raman spectrometer to surgical specimens.

Methods: Samples of nervous tissue, colon cancer tissue, and tissues from surrounding pelvic organs were obtained from 25 patients undergoing colectomy. Raman spectra were obtained by irradiation with the Progeny ${ }^{\mathrm{TM}}$ Raman spectrometer. We looked for characteristic Raman shifts to distinguish nervous tissue from cancer tissue. To improve discrimination between nervous tissue and other tissues, the spectral data were subjected to principal component analysis.

Results: We detected characteristic differences in the spectra at $1,309 \mathrm{~cm}^{-1}, 1,442 \mathrm{~cm}^{-1}$, and $1,658 \mathrm{~cm}^{-1}$. A significant difference was detected at $1,442 \mathrm{~cm}^{-1}$, and accuracy of the modality for identification of nervous tissue was $75 \%$. The addition of principle component analysis (4 components) yielded 100\% sensitivity, $85 \%$ specificity, and $90 \%$, notably increasing accuracy from $75 \%$ to $90 \%$ in discriminating between nervous tissue and cancer tissue.

Conclusions: Raman spectroscopy holds promise for non-invasive intraoperative recognition of nervous tissue. We expect the modality to become a powerful clinical tool, compensating for the lack of tactile feedback intrinsic to minimally invasive colectomy and thus thwarting the risk of postoperative urinary and/ or sexual dysfunction.

Keywords: Autonomic nerve; Raman spectroscopy; colorectal cancer; minimally invasive surgery; postoperative dysfunction

^ ORCID: 0000-0001-5050-4379. 
Submitted Apr 04, 2021. Accepted for publication Jul 14, 2021.

doi: $10.21037 /$ tcr-21-587

View this article at: https://dx.doi.org/10.21037/tcr-21-587

\section{Introduction}

Total mesorectal excision (TME), described as sharp dissection along the surface of the mesorectum, has become a standard surgical technique for resection of colorectal cancer. Although TME has improved oncological outcomes (1), the reported incidence of urinary dysfunction resulting from injury to a pelvic nerve or any nerve feeding into the pelvic plexus is high, ranging from $30 \%$ to $70 \%$ following open TME $(2,3)$. The incidence of male sexual dysfunction after rectal cancer surgery is particularly high, shown in a randomized controlled trial to be about $70 \%$ (4).

Minimally invasive surgery, whether standard laparoscopic or robotic-assisted surgery, is now widely performed as treatment for colorectal cancer $(5,6)$. Although large randomized trials have shown the oncological outcomes of laparoscopic colectomy to be similar to those of open colectomy, short-term outcomes are improved (7-9). The short-term benefits, such as decreased postoperative stay and briefer use of pain relievers, have popularized the laparoscopic approach.

With the introduction of laparoscopic surgery as treatment for colorectal cancer came the expectation that the closer, magnified view would facilitate preservation of the pelvic nerves and improve outcomes in terms of urinary and sexual function. However, several trials showed the frequency of sexual dysfunction to be similar or even higher following laparoscopic TME than that following open TME (10-13). Even robotic surgery, despite its additional advantages, including the stable high-definition threedimensional view, increased surgical dexterity, and improved ergonomics, has not been found to be superior to open or standard laparoscopic surgery for performance of nervesparing rectal cancer surgery (14-16). Postoperative urinary dysfunction and sexual dysfunction due to intraoperative nerve injury remain matters of major concern even with minimally invasive surgery, and nerve-sparing surgery based simply on visual cues is limited. Thus, a new method is needed to reliably identify the pelvic nerves intraoperatively.

Raman spectroscopy is a non-invasive label-free technology used to measure the scattering of light by matter. The Raman spectra reflect molecular vibrations specific to the different atomic species and the chemical bonds that hold molecules together. Raman spectroscopy was first used in the field of chemistry to obtain valuable structural information about samples via molecular vibrations $(17,18)$. Raman spectroscopy is now being applied in the fields of biology and biochemistry to identify the chemical species present in macromolecules, nucleic acids, proteins, and lipids (19), and it has shown promise for diagnosis of lung, breast, and gastroenterological cancers $(20,21)$.

As previously reported, the small, handheld Raman spectrometer, Progeny ${ }^{\mathrm{TM}}$ (Rigaku Analytical Devices, Inc., MA, USA), which acquires even weak signals on 1,064-nm excitation and then records Raman spectra immediately, has shown potential for real-time diagnosis of colorectal cancer (22). We have since speculated that this all-inone Raman spectrometer can be used for intraoperative identification of the autonomic nerves in the pelvis in patients undergoing surgery for colorectal cancer. We tested the possibility of using this spectrometer as an innovative tool for clinical identification of nervous tissue, with the ultimate goal of assisting surgeons in performing nerve-sparing colorectal surgery. We present this article in accordance with the STARD reporting checklist (available at https://dx.doi.org/10.21037/tcr-21-587).

\section{Methods}

\section{Tissue samples}

Tissues used in the study were obtained from 25 patients who, having been diagnosed with advanced colorectal cancer, underwent open or laparoscopic colectomy at Kanagawa Cancer Center between June 2019 and June 2020. Clinical characteristics of these patients, including the clinicopathologic characteristics of their tumors, are described below. All 25 patients provided written, informed consent for anonymized use of their clinical data for study purposes.

Sixty-four tissues samples were obtained from the patients' surgical specimens, and the fresh samples were then prepared as $5 \times 5 \times 5-\mathrm{mm}$ blocks. The samples were of the tumor itself and of normal colon tissue near the edge of the tumor. Some of the specimens were en bloc surgical specimens, and from these specimens we obtained samples of nervous tissue and of bladder, prostate, uterus, ovary, and ureter tissue in addition to colon tissue samples. The 


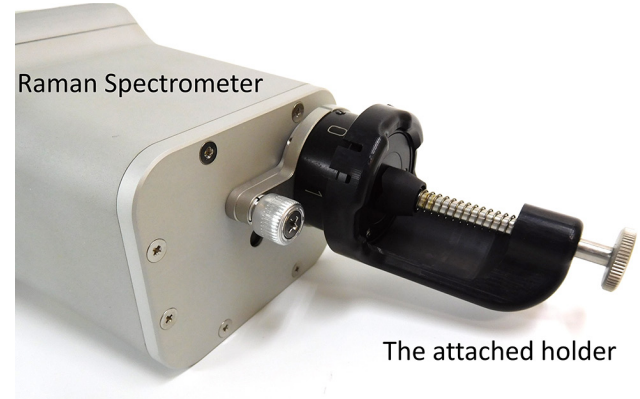

Figure 1 The Progeny ${ }^{\mathrm{TM}}$ (Rigaku Raman Technologies Inc., Tokyo, Japan) Raman spectrometer and tissue sample holder, which is attached with a screw to the front of the device.

study was conducted in accordance with the Declaration of Helsinki (as revised in 2013). The study and all procedures involved were conducted under approval granted by the institutional review board of Kanagawa Cancer Center (IRB number: 2019EKI43), and informed consent was obtained from all 25 patients.

\section{Raman spectrometry}

We analyzed the tissue samples with use of the Progeny ${ }^{\mathrm{TM}}$ spectrometer, as previous reported (22). Each tissue block was placed in the holder attached to the front of the device (Figure 1), the tissue was irradiated at 3-5 random spots, and the Raman spectra were recorded by the device. A total of 181 Raman spectra were expressed in wavenumbers ranging from 800 to $1,800 \mathrm{~cm}^{-1}$.

For the purpose of the study, we compared Raman spectra of 32 nervous tissues against those of 52 colon cancer tissues. We also compared Raman spectra of the 32 nervous tissues against those of normal pelvic organ tissues (49 colon, 9 bladder, 10 prostate, 12 uterus, 9 ovary, and 8 ureter tissues). After irradiation, all tissue blocks were pathologically confirmed to be the tissues of interest.

\section{Statistical analysis}

One hundred ninety-seven shifts were observed in the spectral range of 800 to $1,800 \mathrm{~cm}^{-1}$. We evaluated the intensity of scattered light at each shift and compared the intensities to find the characteristic difference between nervous tissue and colon cancer tissue. Differences were analyzed by KruskalWallis test, with $\mathrm{P}<0.05$ considered statistically significant. The discriminatory power of the intensities at the characteristic shift was evaluated by means of nonparametric receiver operating characteristic (ROC) analysis. The area under the ROC curve (AUC), 95\% confidence interval (95\% CI), sensitivity, specificity, and accuracy were calculated. These statistical analyses were performed with JMP ver. 14 (SAS Institute Inc., Cary, NC, USA).

\section{Discriminate analysis}

To improve discrimination between the nervous tissue and other tissues, the spectral data were analyzed by means of principal component analysis (PCA). We extracted principal components (PCs) from all Raman spectra of the various tissue samples. Each PC accounted for the maximum amount of variance in the data and allowed us to find the characteristic Raman shifts in samples. That is, we reduced the large set of variables for each sample, the 197 spectral shifts from 800 to $1,800 \mathrm{~cm}^{-1}$, to a small set based on PCs that contain specific information about each sample in the large set (22) and performed discriminate analysis with use of the PCs to determine whether the nervous tissue could be identified by Raman spectroscopy. Sensitivity, specificity, and accuracy were calculated. SYSTAT ver. 13 (Systat Software Inc., San Jose, CA, USA) was used for this analysis.

\section{Results}

\section{Patient and tumor characteristics}

The 25 patients who provided samples for the study were 19 men and 6 women ranging in age from 32 to 86 years (median: 72 years) (Table 1). None had undergone chemotherapy or radiation therapy preoperatively. The tumor was located in the left colon in $19(76 \%)$ patients and the right colon in $5(20 \%)$ patients. The tumor in 1 case (4\%) was a fallopian tube cancer that had invaded the colon. The pathological stage was pT3 or pT4 in $22(92 \%)$ patients, and all 7 stage pT4 tumors, i.e., locally advanced tumors, were treated by en bloc resection. The tumor was found to be a Borrmann type II advanced cancer in 9 (72\%) patients (23).

\section{Analysis of the Raman spectra}

Raman spectra of the nervous tissue and of the colon cancer tissue are shown in Figure 2A. Characteristic differences in the spectra were detected as high peaks at $1,309 \mathrm{~cm}^{-1}$, $1,442 \mathrm{~cm}^{-1}$, and $1,658 \mathrm{~cm}^{-1}$. The first PC, which shows 
Table 1 Characteristics of patients $(n=25)$ and clinicopathologic characteristics of their tumors

\begin{tabular}{|c|c|}
\hline & Value \\
\hline Age & $72(32-86)$ years \\
\hline Sex ratio (male/female) & $19 / 6$ \\
\hline \multicolumn{2}{|l|}{ Tumor location $^{\dagger}$} \\
\hline Right colon & 5 \\
\hline Left colon & 19 \\
\hline \multicolumn{2}{|l|}{ Postoperative pT stage $^{\dagger}$} \\
\hline $\mathrm{T} 2$ & 2 \\
\hline T3 & 15 \\
\hline $\mathrm{T} 4$ & 7 \\
\hline \multicolumn{2}{|l|}{ Postoperative $\mathrm{pN}$ stage ${ }^{\dagger}$} \\
\hline No & 9 \\
\hline $\mathrm{N} 1$ & 11 \\
\hline $\mathrm{N} 2$ & 4 \\
\hline \multicolumn{2}{|l|}{ 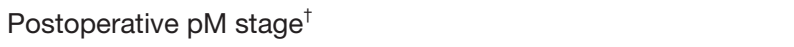 } \\
\hline MO & 19 \\
\hline M1 & 5 \\
\hline \multicolumn{2}{|l|}{ Histologic type $^{\dagger}$} \\
\hline Well differentiated & 8 \\
\hline Moderately differentiated & 14 \\
\hline Poorly differentiated & 2 \\
\hline \multicolumn{2}{|c|}{ Morphologic type ${ }^{\dagger}$ (Borrmann classification) } \\
\hline Type I & 1 \\
\hline Type II & 19 \\
\hline Type III & 3 \\
\hline Type IV & 0 \\
\hline Type V & 1 \\
\hline
\end{tabular}

Median (range) values or number of patients are shown. ${ }^{\dagger}$, Excluding the case of fallopian tube cancer that had invaded the colon.

factors common to all Raman spectra, confirmed these differences in the spectra between nervous tissue and colon cancer tissue (Figure 2B). To simplify the diagnostic criteria, we evaluated the possibility of using only the intensity of scattered light at $1,309 \mathrm{~cm}^{-1}, 1,442 \mathrm{~cm}^{-1}$, or $1,658 \mathrm{~cm}^{-1}$. Statistically significant differences were found at $1,442 \mathrm{~cm}^{-1}$; the intensities at 1,309 and $1,658 \mathrm{~cm}^{-1}$ differed
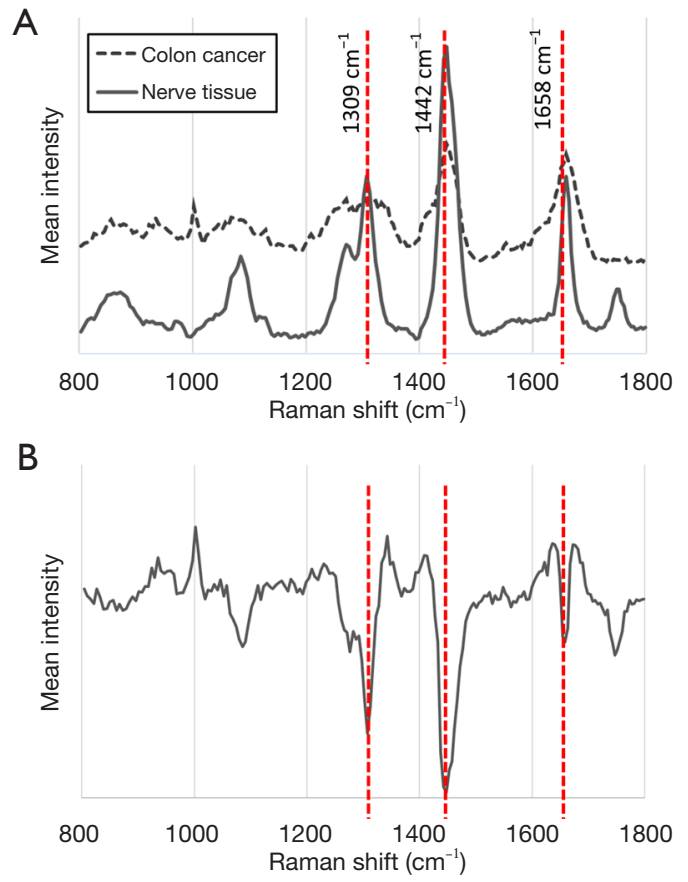

Figure 2 Spectrograms showing (A) averaged Raman spectra from nerve tissue and colon cancer tissue, and (B) the first principal component (PC) of all Raman spectra. Both showed a high peak and characteristic variance at $1,309 \mathrm{~cm}^{-1}, 1,442 \mathrm{~cm}^{-1}$, and $1,658 \mathrm{~cm}^{-1}$ that differed between nerve tissue and colon cancer tissue.

only slightly (Figure 3A, Table 2). ROC analysis showed that the differences in these intensities at the Raman shift distinguished nervous tissue from colon cancer tissue, with a maximum AUC of 0.618 [95\% CI: 0.468-0.748) for $1,658 \mathrm{~cm}^{-1}$, maximum accuracy $=75 \%$ (sensitivity $=56 \%$, specificity $=87 \%$ ) for $1442 \mathrm{~cm}^{-1}$; Figure 3B, Table 2].

To more powerfully distinguish nervous tissue from cancer tissue, we obtained successive PCs from all samples (Figure 4). The first PC accounted for the maximum amount of variance present in the spectral data set, whereas successive PCs accounted for features contributing progressively smaller variances. We calculated PC scores for each sample and then performed discriminate analysis based on these scores (24). We found that the first PC score reliably distinguished nervous tissue from cancer tissue with $100 \%$ sensitivity, $85 \%$ specificity, and $90 \%$ diagnostic accuracy (Table 3). When we used the first and second PC scores, the percentages improved, and when we used all 4 PC scores (Figure 4), the analysis fully discriminated between the nervous tissue and colon cancer tissue, with 100\% diagnostic accuracy, as shown in Table 3. 


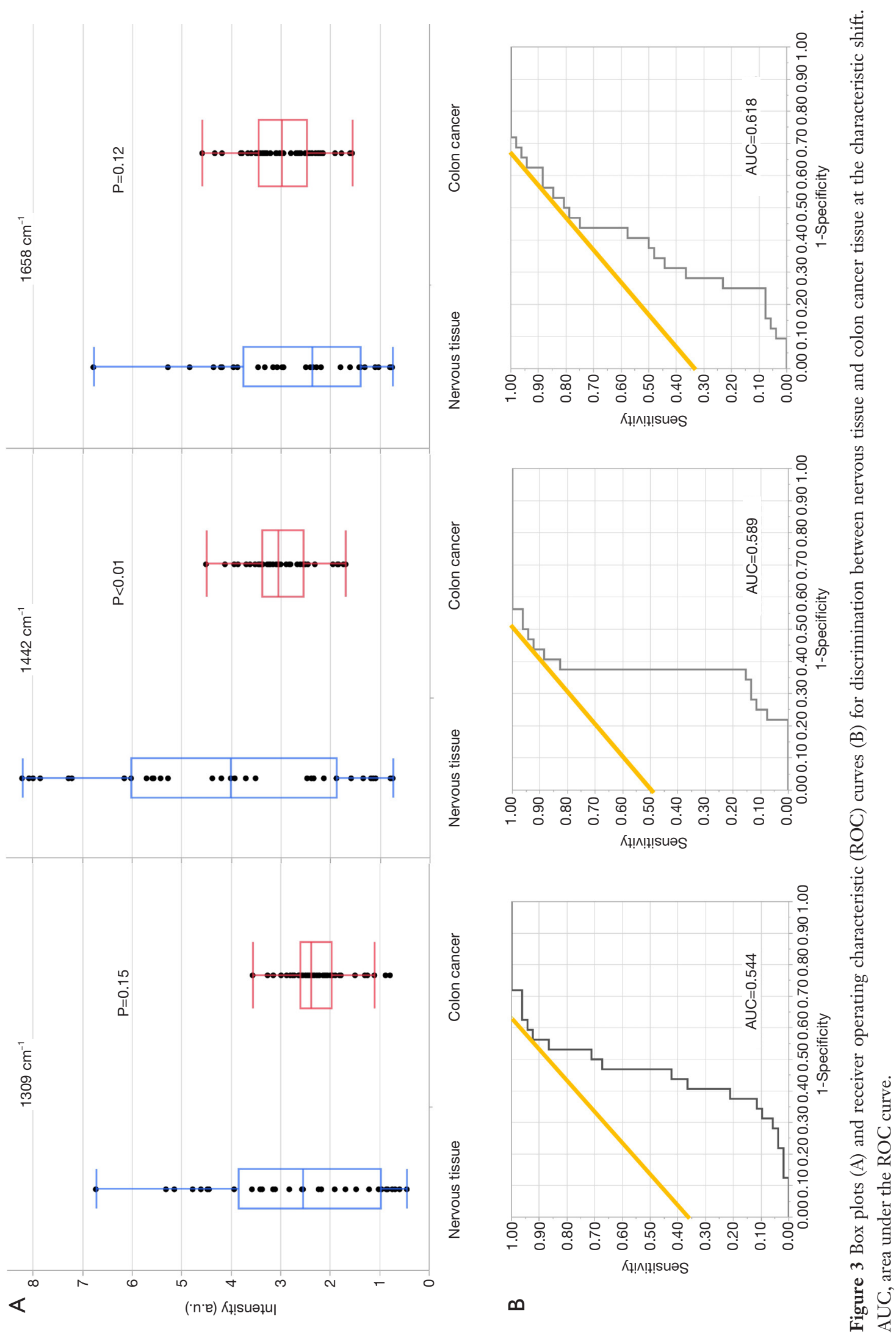


Table 2 Characteristic Raman shifts that differed between nervous tissue and colon cancer tissue

\begin{tabular}{lcccccc}
\hline Raman shift & P value & AUC & $95 \% \mathrm{Cl}$ & Sensitivity\% & Specificity\% & Accuracy\% \\
\hline $1,309 \mathrm{~cm}^{-1}$ & 0.15 & 0.544 & $0.388-0.692$ & $53 \%$ & $60 \%$ & $57 \%$ \\
$1,442 \mathrm{~cm}^{-1}$ & $<0.01$ & 0.589 & $0.495-0.674$ & $56 \%$ & $87 \%$ & $75 \%$ \\
$1,658 \mathrm{~cm}^{-1}$ & 0.12 & 0.618 & $0.468-0.748$ & $56 \%$ & $58 \%$ & $57 \%$ \\
\hline
\end{tabular}

AUC, area under the receiver operating characteristic curve; $95 \% \mathrm{Cl}, 95 \%$ confidence interval. Sensitivity, specificity, and accuracy are shown as the results of discriminant analysis used to identify the characteristic Raman shift.

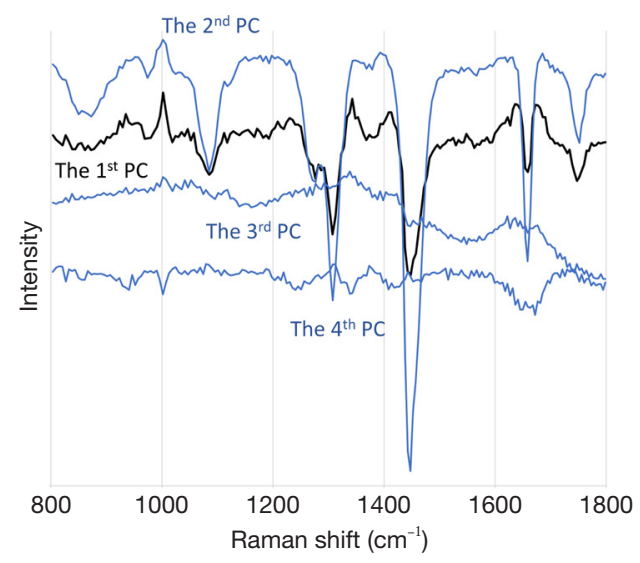

Figure 4 The first to fourth principal components (PCs) were obtained from all Raman spectra of samples. Each PC accounts for variance in the total data set and reveals the characteristic difference in Raman shifts.

We investigated the possibility of discrimination between nervous tissue and normal colon tissue, bladder, prostate, uterus, ovary, and ureter tissues based on scores for the 4 PCs of the spectra. The resulting diagnostic accuracy was high, at $90 \%$ to $100 \%$ (Table 4 ).

\section{Discussion}

Within the narrow pelvic cavity, various nerves and nerve plexuses lie in close proximity to the rectum. These include the hypogastric nerve, pelvic splanchnic nerve, and pelvic nerve plexus, including the neurovascular bundles that travel through the pelvic floor. Nerve-sparing surgery for rectal cancer remains imperfect. Nerve-sparing TME is the gold standard for surgical treatment of rectal cancer, but in a randomized controlled trial (JCOG0212), urinary dysfunction and sexual dysfunction were recognized in $58 \%$ and $68 \%$ of patients, respectively, even when the surgery was performed by experienced surgeons at high volume centers $(2,4)$. This is because courses of the autonomic
Table 3 Discrimination between nervous tissue and colon cancer tissue by the first principal component (PC), first and second PCs, and all $4 \mathrm{PCs}$

\begin{tabular}{|c|c|c|}
\hline & \multicolumn{2}{|c|}{ Pathological diagnosis } \\
\hline & $\begin{array}{l}\text { Nervous } \\
\text { tissue }\end{array}$ & $\begin{array}{c}\text { Colon cancer } \\
\text { tissue }\end{array}$ \\
\hline \multicolumn{3}{|c|}{ Raman diagnosis by first PC } \\
\hline Nervous tissue & 32 & 8 \\
\hline Colon cancer tissue & 0 & 44 \\
\hline Total & 32 & 52 \\
\hline \multicolumn{3}{|c|}{ Sensitivity $100 \%$, specificity $85 \%$, accuracy $90 \%$} \\
\hline \multicolumn{3}{|c|}{ Raman diagnosis by first and second PCs } \\
\hline Nervous tissue & 32 & 5 \\
\hline Colon cancer tissue & 0 & 47 \\
\hline Total & 32 & 52 \\
\hline \multicolumn{3}{|c|}{ Sensitivity $100 \%$, specificity $90 \%$, accuracy $94 \%$} \\
\hline \multicolumn{3}{|c|}{ Raman diagnosis by 4 PCs } \\
\hline Nervous tissue & 32 & 0 \\
\hline Colon cancer tissue & 0 & 52 \\
\hline Total & 32 & 52 \\
\hline
\end{tabular}

Numbers of tissue samples are shown.

nerves are complex and vary from person to person. Surgeons must gently push aside these nerves during the surgery, but they have no means of identifying these nerves except by direct vision. Because the need exists not only to remove the cancer but also preserve nerve function, an objective method for recognizing the nerves is needed.

As reported herein, we experimented with use of a handheld Raman spectrometer to quickly and precisely identify autonomic nerves in the pelvis. We first evaluated the possibility of finding the specific signal intensity in the 197 Raman shifts we obtained and focused on the high peaks 
Table 4 Discrimination (Raman diagnosis) between nervous tissue and other pelvic organ tissues by the 4 principal components

\begin{tabular}{|c|c|c|c|}
\hline \multirow[b]{2}{*}{ Pathological diagnosis } & \multicolumn{2}{|c|}{ Raman diagnosis } & \multirow[b]{2}{*}{ Tota } \\
\hline & $\begin{array}{l}\text { Nervous } \\
\text { tissue }\end{array}$ & $\begin{array}{c}\text { Non-nervous } \\
\text { tissue }\end{array}$ & \\
\hline Nervous tissue & 32 & 0 & 32 \\
\hline Colon cancer tissue & 0 & 52 & 52 \\
\hline \multicolumn{4}{|c|}{ Sensitivity $100 \%$, specificity $100 \%$, accuracy $100 \%$} \\
\hline Nervous tissue & 32 & 0 & 32 \\
\hline Normal colon tissue & 2 & 47 & 49 \\
\hline \multicolumn{4}{|c|}{ Sensitivity $100 \%$, specificity $96 \%$, accuracy $98 \%$} \\
\hline Nervous tissue & 27 & 5 & 32 \\
\hline Bladder & 0 & 9 & 9 \\
\hline \multicolumn{4}{|c|}{ Sensitivity $84 \%$, specificity $100 \%$, accuracy $88 \%$} \\
\hline Nervous tissue & 28 & 4 & 32 \\
\hline Prostate & 0 & 10 & 10 \\
\hline \multicolumn{4}{|c|}{ Sensitivity $88 \%$, specificity $100 \%$, accuracy $90 \%$} \\
\hline Nervous tissue & 31 & 1 & 32 \\
\hline Uterus & 0 & 12 & 12 \\
\hline \multicolumn{4}{|c|}{ Sensitivity $97 \%$, specificity $100 \%$, accuracy $98 \%$} \\
\hline Nervous tissue & 28 & 4 & 32 \\
\hline Ovary & 0 & 9 & 9 \\
\hline \multicolumn{4}{|c|}{ Sensitivity $88 \%$, specificity $100 \%$, accuracy $90 \%$} \\
\hline Nervous tissue & 29 & 3 & 32 \\
\hline Ureter & 1 & 7 & 8 \\
\hline
\end{tabular}

Numbers of tissue samples are shown.

at $1,442 \mathrm{~cm}^{-1}, 1,309^{-1}$, and $1,658 \mathrm{~cm}^{-1}$. The pelvic nerve plexus is supplied by both myelinated and unmyelinated nerve fibers. Myelin sheaths consist of a large amount of adipose tissue, expressing phosphatidylethanolamine and sphingomyelin, and the fibrous connective tissue that surrounds the nerves consists mainly of collagen. These facts are consistent with the following: A Raman shift at $1,309 \mathrm{~cm}^{-1}$ is associated with $\mathrm{CH}_{2}$ and $\mathrm{CH}_{3} \mathrm{CH}_{2}$ bending vibration from collagen, and at $1,442 \mathrm{~cm}^{-1}$, it is associated with $\mathrm{CH}_{2}$ bending vibration from both collagen and lipid. The peak at $1,660 \mathrm{~cm}^{-1}$ corelates with the lipid $\mathrm{C}=\mathrm{C}$ stretch band (25). We found the Kruskal-Wallis-based analysis to be useful and simple for discriminating between the nervous tissue and cancer tissue by means of Raman spectroscopy, with relatively good diagnostic accuracy of $57 \%$ to $75 \%$. However, we found there was still room to improve the discriminatory power.

To enhance accuracy, we applied PCA. We succeeded in fully distinguishing the nervous tissue from cancer tissue using 4 PC scores. Calculating PC scores usually takes a long time, as noted previously from a study incorporating 10 PCs $(22,26)$. We used only 4 PCs, shortening the process considerably.

We then applied this method to improve classification of nervous tissue $v s$. pelvic organ tissues including normal colorectal, bladder, prostate, uterus, ovary, and ureter tissues, and we found accuracy to be high. Our PCA of the Raman spectra was also useful for distinguishing between cancer tissue and pelvic organ tissues, with accuracy ranging from $89 \%$ to $100 \%$ (data not shown). This means that our method will allow for rapid and precise identification not only of nervous tissue but also of the pelvic organs.

Minamikawa et al. reported recognition of nervous tissue by means of Raman microspectroscopy (27). Their study was based on the use of an Nd:YAG laser at an excitation wavelength of $532 \mathrm{~nm}$. , However, the short excitation wavelengths of $532 \mathrm{~nm}$ and $785 \mathrm{~nm}$ damage tissues and result in a low signal-to-noise ratio and high level of background fluorescence. Our device with the 1064-nm excitation light is especially suitable for in vivo assessment because of the minimal effects in tissue, which is an advantage in terms of clinical applicability. In addition, most previously reported data were derived from use of nonportable spectrometers that had little in common between institutions, and the quality of the measurements was not verified. The spectrometer we used for the study described herein is a commercially available handheld spectrometer that provides good quality and highly reproducible data.

Minimally invasive surgery, whether standard laparoscopic surgery or robotic surgery, is becoming increasingly common. However, the element of tactile feedback is missing with both of these approaches, an element that remains important if the pelvic nerves are to be recognized and preserved during surgery for colorectal cancer. Results of our study indicate that it will be possible to improve postoperative urination, defecation, and sexual function by accurately and objectively identifying the complex autonomic nerves of the pelvis intraoperatively. We expect eventual incorporation of our technology into the performance of minimally invasive colorectal surgery, whether standard laparoscopic surgery or robotic surgery, 
to compensate for the lack of tactile feedback and allow for precise identification and manipulation of the pelvic nerves.

In conclusion, we have shown that Raman spectroscopy, performed with a handheld spectrometer as described, can be used for recognition of nervous tissue. Although results of our study should be considered preliminary, we consider such application of this technology to be promising for intraoperative identification of nervous tissue, and we are now planning further study in cadavers. We believe Raman spectroscopy performed with a handheld device will become a clinically powerful tool for rapid, non-invasive recognition of the pelvic nerves and thus prevent the types of postoperative dysfunction that can follow minimally invasive colorectal surgery.

\section{Acknowledgments}

We would like to thank Prof. Tina Tajima for assistance in reviewing the manuscript to ensure proper English expression. The authors thank Rigaku Corporation for their technical support related to the use of Progeny ${ }^{\mathrm{TM}}$.

Funding: This work was supported by JSPS KAKENHI (Grant Number 19K09228).

\section{Footnote}

Reporting Checklist: The authors have completed the STARD reporting checklist. Available at https://dx.doi. org/10.21037/tcr-21-587

Data Sharing Statement: Available at https://dx.doi. org/10.21037/tcr-21-587

Conflicts of Interest: All authors have completed the ICMJE uniform disclosure form (available at https://dx.doi. org/10.21037/tcr-21-587). All authors report that this work was supported by JSPS KAKENHI (Grant Number 19K09228). The authors thank Rigaku Corporation for their technical support related to the use of Progeny ${ }^{\mathrm{TM}}$. Hirotada Kagoshima reports he is an employee of Rigaku Corporation.

Ethical Statement: The authors are accountable for all aspects of the work in ensuring that questions related to the accuracy or integrity of any part of the work are appropriately investigated and resolved. The study was conducted in accordance with the Declaration of Helsinki (as revised in 2013). The study was approved by the institutional review board of Kanagawa Cancer Center (approval number: 2019EKI43), and informed consent was taken from all the patients. This work complied with the current laws in Japan.

Open Access Statement: This is an Open Access article distributed in accordance with the Creative Commons Attribution-NonCommercial-NoDerivs 4.0 International License (CC BY-NC-ND 4.0), which permits the noncommercial replication and distribution of the article with the strict proviso that no changes or edits are made and the original work is properly cited (including links to both the formal publication through the relevant DOI and the license). See: https://creativecommons.org/licenses/by-nc-nd/4.0/.

\section{References}

1. Ridgway PF, Darzi AW. The role of total mesorectal excision in the management of rectal cancer. Cancer Control 2003;10:205-11.

2. Ito M, Kobayashi A, Fujita S, et al. Urinary dysfunction after rectal cancer surgery: Results from a randomized trial comparing mesorectal excision with and without lateral lymph node dissection for clinical stage II or III lower rectal cancer (Japan Clinical Oncology Group Study, JCOG0212). Eur J Surg Oncol 2018;44:463-8.

3. Karlsson L, Bock D, Asplund D, et al. Urinary dysfunction in patients with rectal cancer: a prospective cohort study. Colorectal Dis 2020;22:18-28.

4. Saito S, Fujita S, Mizusawa J, et al. Male sexual dysfunction after rectal cancer surgery: Results of a randomized trial comparing mesorectal excision with and without lateral lymph node dissection for patients with lower rectal cancer: Japan Clinical Oncology Group Study JCOG0212. Eur J Surg Oncol 2016;42:1851-8.

5. Villano AM, Zeymo A, Houlihan BK, et al. Minimally Invasive Surgery for Colorectal Cancer: Hospital Type Drives Utilization and Outcomes. J Surg Res 2020;247:180-9.

6. Wells KO, Senagore A. Minimally Invasive Colon Cancer Surgery. Surg Oncol Clin N Am 2019;28:285-96.

7. Clinical Outcomes of Surgical Therapy Study Group; Nelson H, Sargent DJ, et al. A comparison of laparoscopically assisted and open colectomy for colon cancer. N Engl J Med 2004;350:2050-9.

8. Guillou PJ, Quirke P, Thorpe H, et al. Short-term endpoints of conventional versus laparoscopic-assisted surgery in patients with colorectal cancer (MRC 
CLASICC trial): multicentre, randomised controlled trial. Lancet 2005;365:1718-26.

9. Veldkamp R, Kuhry E, Hop WC, et al. Laparoscopic surgery versus open surgery for colon cancer: shortterm outcomes of a randomised trial. Lancet Oncol 2005;6:477-84.

10. Quah HM, Jayne DG, Eu KW, et al. Bladder and sexual dysfunction following laparoscopically assisted and conventional open mesorectal resection for cancer. Br J Surg 2002;89:1551-6.

11. Morino M, Parini U, Allaix ME, et al. Male sexual and urinary function after laparoscopic total mesorectal excision. Surg Endosc 2009;23:1233-40.

12. Jayne DG, Brown JM, Thorpe H, et al. Bladder and sexual function following resection for rectal cancer in a randomized clinical trial of laparoscopic versus open technique. Br J Surg 2005;92:1124-32.

13. Andersson J, Abis G, Gellerstedt M, et al. Patient-reported genitourinary dysfunction after laparoscopic and open rectal cancer surgery in a randomized trial (COLOR II). Br J Surg 2014;101:1272-9.

14. Jayne D, Pigazzi A, Marshall H, et al. Effect of RoboticAssisted vs Conventional Laparoscopic Surgery on Risk of Conversion to Open Laparotomy Among Patients Undergoing Resection for Rectal Cancer: The ROLARR Randomized Clinical Trial. JAMA 2017;318:1569-80.

15. Ozeki S, Maeda K, Hanai T, et al. Effects of robotic rectal surgery on sexual and urinary functions in male patients. Surg Today 2016;46:491-500.

16. Luca F, Craigg DK, Senthil M, et al. Sexual and urinary outcomes in robotic rectal surgery: review of the literature and technical considerations. Updates Surg 2018;70:415-21.

17. Blacksberg J, Rossman GR, Gleckler A. Time-resolved Raman spectroscopy for in situ planetary mineralogy. Appl Opt 2010;49:4951-62.

Cite this article as: Sato $S$, Kagoshima $H$, Shiozawa $M$, Nukada S, Iguchi K, Mikayama Y, Oshima T, Numata M, Tamagawa H, Rino Y, Masuda M, Tanaka K. Automated non-invasive identification of pelvic autonomic nerves with a handheld Raman spectrometer and potential application to nerve-sparing colorectal surgery: a preliminary study in surgical specimens. Transl Cancer Res 2021;10(9):3921-3929. doi: $10.21037 /$ tcr-21-587
18. Mukherjee P, Lim SJ, Wrobel TP, et al. Measuring and Predicting the Internal Structure of Semiconductor Nanocrystals through Raman Spectroscopy. J Am Chem Soc 2016;138:10887-96.

19. Hanlon EB, Manoharan R, Koo TW, et al. Prospects for in vivo Raman spectroscopy. Phys Med Biol 2000;45:R1-59.

20. Min YK, Yamamoto T, Kohda E, et al. 1064 nm nearinfrared multichannel Raman spectroscopy of fresh human lung tissues. J Raman Spectrosc 2005;36:73-6.

21. Kallaway C, Almond LM, Barr H, et al. Advances in the clinical application of Raman spectroscopy for cancer diagnostics. Photodiagnosis Photodyn Ther 2013;10:207-19.

22. Sato S, Sekine R, Kagoshima H, et al. All-in-one Raman spectroscopy approach to diagnosis of colorectal cancer: analysis of spectra in the fingerprint regions. J Anus Rectum Colon 2019;3:84-90.

23. The Paris endoscopic classification of superficial neoplastic lesions: esophagus, stomach, and colon: November 30 to December 1, 2002. Gastrointest Endosc 2003;58:S3-43.

24. Kawabata T, Mizuno T, Okazaki S, et al. Optical diagnosis of gastric cancer using near-infrared multichannel Raman spectroscopy with a 1064-nm excitation wavelength. J Gastroenterol 2008;43:283-90.

25. Huang W, Wu S, Chen M, et al. Study of both fingerprint and high wavenumber Raman spectroscopy of pathological nasopharyngeal tissues. J Raman Spectrosc 2015;46:537-44.

26. Kawabata T, Kikuchi H, Okazaki S, et al. Near-infrared multichannel Raman spectroscopy with a $1064 \mathrm{~nm}$ excitation wavelength for ex vivo diagnosis of gastric cancer. J Surg Res 2011;169:e137-43.

27. Minamikawa T, Harada Y, Koizumi N, et al. Label-free detection of peripheral nerve tissues against adjacent tissues by spontaneous Raman microspectroscopy. Histochem Cell Biol 2013;139:181-93. 